\title{
Pembuatan Sistem Informasi Administrasi Tenaga Pendidik Di Taman Kanak-Kanak Berbasis Web
}

\author{
Catur Puput Wuladari', Mardiyanto ${ }^{2}$ \\ ${ }^{1}$ STT Cahaya Surya Kediri \\ ${ }^{2}$ STT Cahaya Surya Kediri \\ E-mail: ${ }^{1}$ cpw.94@gmail.com, ${ }^{2}$ mardiyanto@ cahayasurya.ac.id
}

\begin{abstract}
Abstrak
Saat ini para tenaga pendidik masih menggunakan cara yang manual dalam mengerjakan administrasi tenaga penididik, sehingga membutuhkan waktu yang sangat lama dan hal tersebut dapat memungkinkan terjadinya kerusakan atau hilangnya data baik data anak didik atau data tenaga pendidik. Informasi berarti pemberitahuan atau kabar tentang sesuatu. Sistem informasi berarti perangkat unsur yang secara teratur saling berkaitan sehingga membentuk suatu totalitas yang berfungsi tentang pemberitahuan atau kabar tentang sesuatu. Administrasi berarti usaha dan kegiatan yang berkaitan dengan penyelenggaraan kebijakan untuk mencapai tujuan. Tenaga pendidik berari tenaga kependidikan yang bertugas sebagai pembimbing, pengajar dan atau pelatih peserta didik mengenai akhlaq dan kecerdasan pikiran. Jadi, setelah menerapkan sistem informasi administrasi tenaga pendidik menjadi mudah dalam menyimpan data administrasi tenaga pendidik dan data anak didik.
\end{abstract}

Kata Kunci-sistem informasi, administrasi, tenaga pendidik.

\section{PENDAHULUAN}

Di dunia globalisasi yang berkembang pesat saat ini, menuntut setiap individu memiliki ketrampilan di bidang teknologi. Selama ini masih ada beberapa instansi pemerintah khususnya bidang pendidikan masih menggunakan cara yang manual dimana dari segi efisiensi waktu sangat tidak maksimal terhadap hasil kerjanya. Belakangan ini berbagai teknologi telah muuncul dan berkembang dalam bidang pendidikan, diantara teknologi-teknologi baru ini ada teknologi software atau perangkat lunak.

Teknologi diciptakan dengan tujuan agar mempermudah manusia atau pemakai teknologi tersebut di dalam aktivitasnya sehari-hari. Khususnya di bidang pendidikan telah diciptakan berbagai bentuk program software yang dapat digunakan sesuai dengan fungsi-fungsi bidang pendidikan yang diinginkan.

Saat ini para tenaga pendidik masih menggunakan cara yang manual dalam pendataan anak didik, pendataan tenaga pendidik, pembuatan rencana pelaksanaan pembelajaran harian (RPPH), jurnal mengajar dan laporan hasil prestasi belajar anak didik atau rapor semester. Sehingga, membutuhkan waktu yang sangat lama dan hal tersebut dapat memungkinkan terjadinya kerusakan atau hilangnya data baik anak didik atau tenaga pendidik.

Untuk mencegah terjadinya kerusakan atau hilangnya data, penyusun membuat sebuah program sistem infomasi berbasis web pada taman kanak-kanak HM PGRI 
Sonorejo untuk membudahkan para tenaga pendidik dalam menyimpan arsip sekolah baik data pendidik atau administrasi tenaga pendidik.

\section{ADMINITRASI TENAGA PENDIDIK}

\subsection{Administrasi}

Administrasi adalah kegiatan kelompok yang mengadakan kerjasama untuk menyelesaikan tugas bersama-sama ${ }^{[2]}$.

Administrasi berarti usaha kegiatan yang berkaitan dengan penyelenggaraan kebijakan untuk mencapai tujuan ${ }^{[4]}$.

Fungsi administrasi, jika dihubungkan dengan administrasi pendidik maka bisa diartikan bahwa hal ini merupakan upaya peningkatan efektifitas guru, dosen, dan lainlain untuk mencapai tujuan pendidikan itu sendiri.

\subsection{Fungsi Administrasi}

1. Mencatat alat-alat perlengkapan organisasi dan kegiatan-kegiatan ke dalam buku administrasi

2. Memelihara buku administrasi.

3. Menyediakan, melengkapi, dan mengola buku administrasi.

4. Mengerjakan buku-buku administrasi sesuai dengan ketentuan-ketentuan yang berlaku.

\subsection{Tenaga pendidik}

Pendidik merupakan tenaga profesional yang bertugas merencanakan dan melaksanan proses pembelajaran, menilai hasil pembelajaran, melakukan pembimbingan dan pelatihan, serta melakukan penelitian dan pegabdian kepada masyarakan, terutama bagi pendidik pada perguruan tinggi. Sedangkan di indonesia pendidik lebih biasa disebut dengan guru $^{[1]}$.

Tenaga pendidik berarti tenaga kependidikan yang bertugas sebagai pembimbing, pengajar dan atau pelatih peserta didik mengenai akhlaq dan kecerdasan pikiran ${ }^{[4]}$.

\subsection{Tugas Tenaga Pendidik}

1. Membuat program kerja kelas.

2. Melaksanakan kegiatan bimbingan, arahan, serta pembinaan kepada siswa.

3. Menyusun pengelolaan kelas meliputi denah tempat duduk siswa dan menseting suasana kelas sesuai dengan situasi dan kondisi.

4. Menyusun administrasi kelas meliputi jadwal pelajaran, presensi, jurnal, rpp,dan tata tertib siswa, serta penilaian siswa.

5. Menyusun statistik perkembangan siswa.

Menyusun laporan kegiatan kelas secara berkala.

\section{HASIL DAN PEMBAHASAN}

\subsection{Perancangan Sistem}

Perancangan sistem merupakan suatu tahapan pengembangan perangkat lunak untuk meningkatkan efektifitas kerja agar dapat memenuhi hasil yang diinginkan. Perancangan sistem bertujuan untuk memberikan gambaran yang jelas dan rancan bangun sesuai dengan user atau pemakaian sisem itu sendiri. Perancangan sistem atau design dilakukan apabila dari tahap analisa sistem telah selesai dilakukan.Pada bagian ini akan dibahas hal-hal mengenai sistem informasi administrasi tenaga pendidik 
dengan bentuk keterkaitan dengan bentuk context diagram dan data flow diagram dari administrasi tenaga pendidik yang berkaitan antara komponen yang satu dengan komponen yang lain.

\subsection{Context Diagram}

Berikut ini adalah hasil analisa yang dituangkan dalam format context diagram tentang sistem informasi administrasi tenaga pendidik di taman kanak-kanak HM PGRI Sonorejo, sebagai berikut:

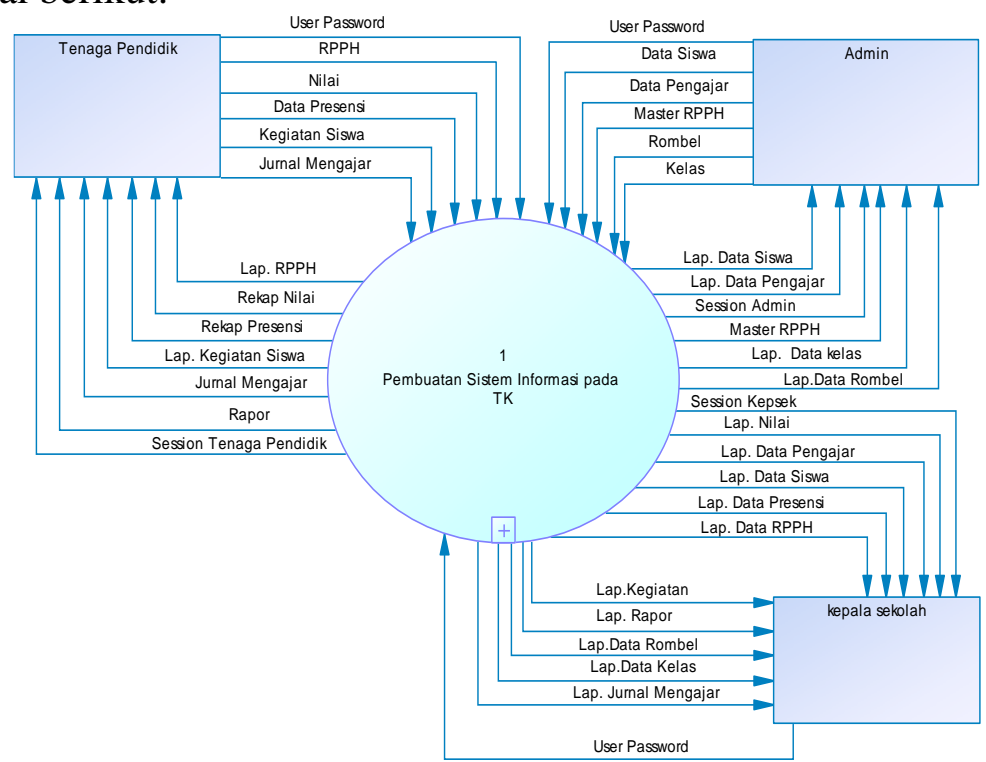

\subsection{Data Flow Diagram}

Gambar 1 Context Diagram

pada data flow diagram merupakan pengembangan dari context diagram. Level demi level akan lebih jelas dipahami dalam bentuk DFD, diagram ini merupakan gambaran secara khusus dari sebuah sistem. Berikut gambaran sistem dengan DFD :

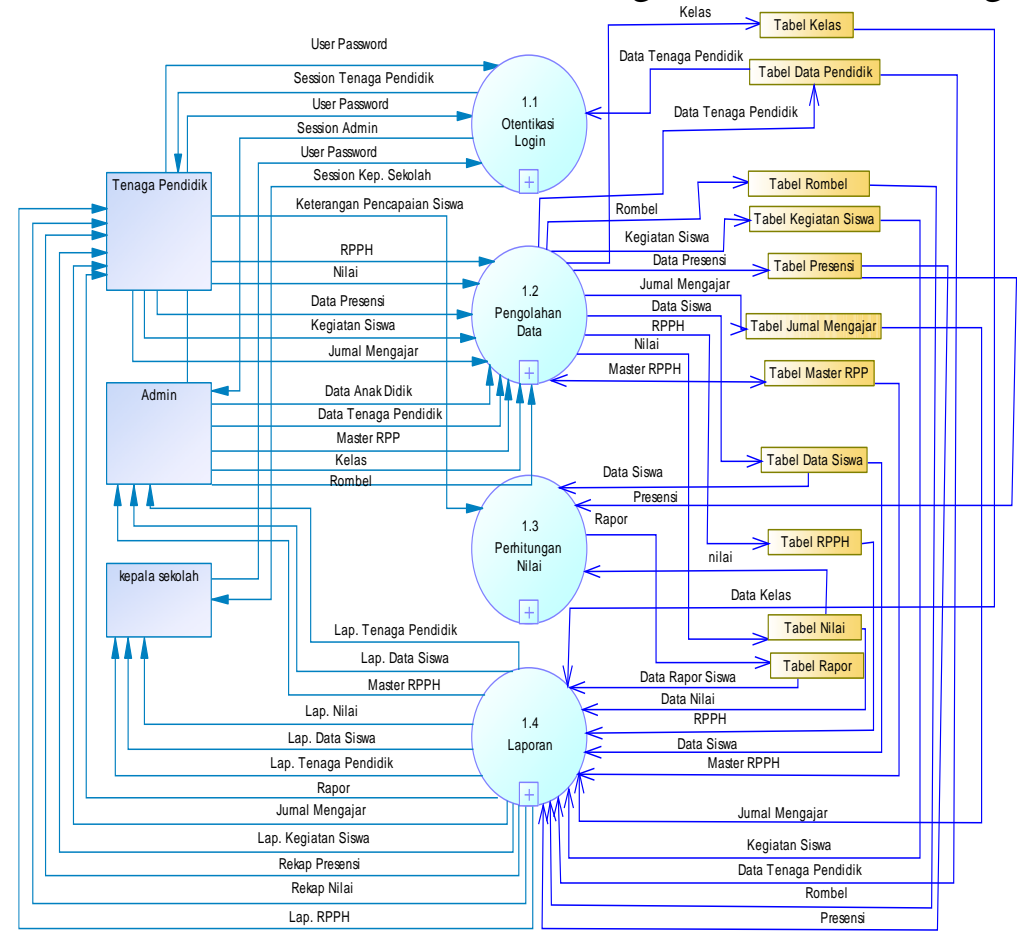

Gambar 2. Data Flow Diagram 


\subsection{Entity Relationship Diagram ( ERD)}

Hubungan entitas - entitas dari sistem rawat inap yang dibuat dapat digambarkan sebagai berikut:

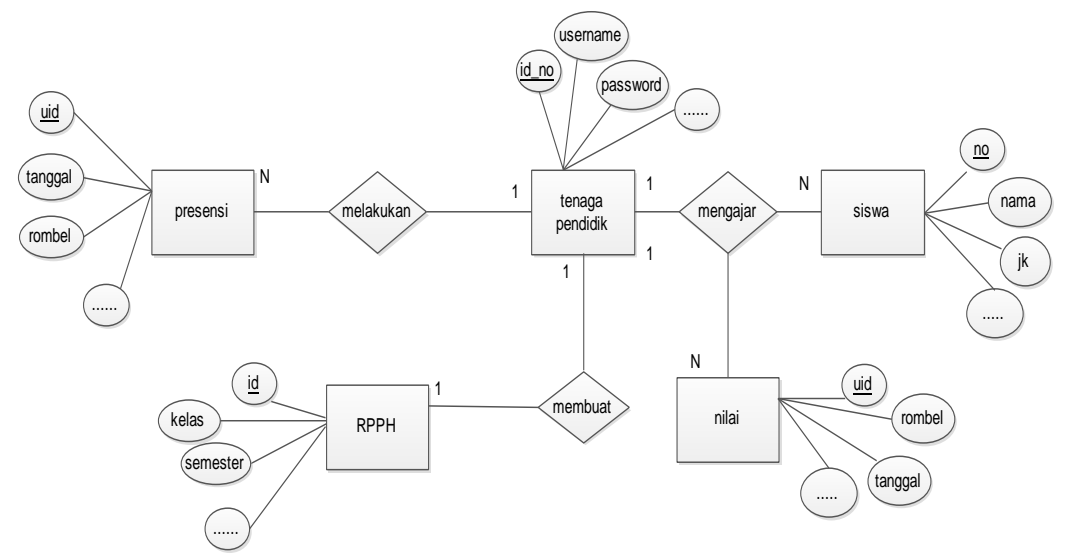

Gambar 3. Entity Relationship Diagram Sistem Administrasi Tenaga Pendidik

\subsection{Form Login}

Halaman ini sebagai security atau pengaman sistem. Admin, tenaga pendidik dan kepala sekolah harus melakukan login dengan memasukkan password dan username terlebih dahulu untuk masuk ke dalam sistem.

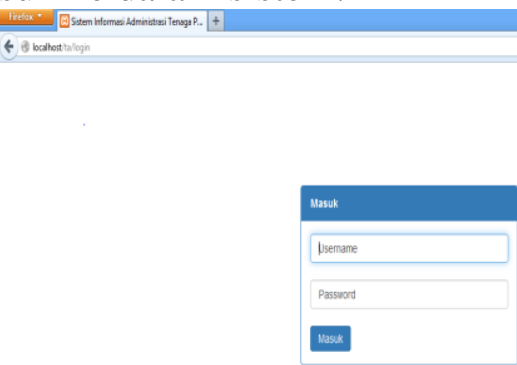

Gambar 4. Halaman Login

\subsection{Halaman Utama Admin}

Halaman ini berisi banyak form seperti form data-data, rombongan belajar, kelas, laporan dan logout. Admin dapat menginputkan data-data pada form ini dengan memilih salah satu form yang diinginkan.

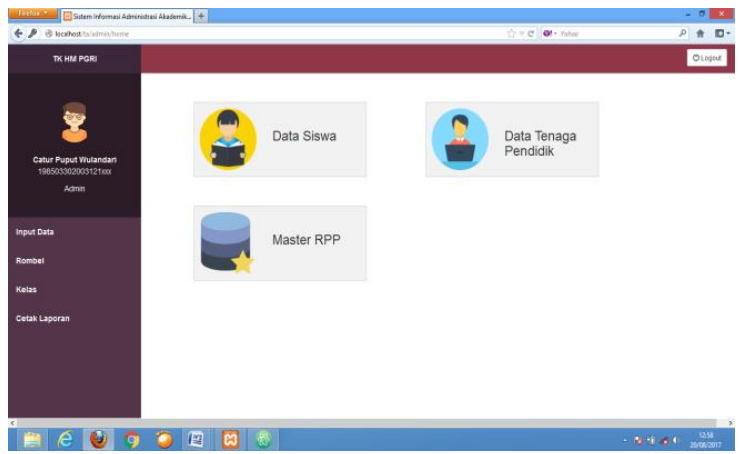




\section{Gambar 5. Halaman Utama Admin}

\subsection{Halaman Data Anak Didik}

Halaman data anak didik memuat nformasi seluruh anak didik yang telah teregristrasi dalam sistem. Data yang ditampilkan halaman ini adalah ringkasan data dari masing-masing anak didik. Dalam halaman ini juga terdapat tombol tambah yang berfungsi untuk menambah data anak didik baru ke dalam sistem.

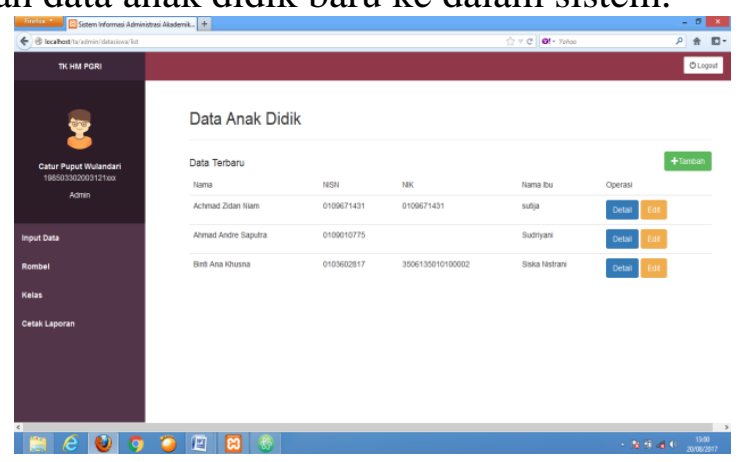

Gambar 6. Halaman Data Anak Didik

\subsection{Halaman Data Tenaga Pendidik}

Halaman data tenaga pendidik memuat nformasi seluruh tenaga pendidik yang telah teregristrasi dalam sistem. Data yang ditampilkan halaman ini adalah ringkasan data dari masing-masing tenaga pendidik. Dalam halaman ini juga terdapat tombol tambah yang berfungsi untuk menambah data tenaga pendidik baru ke dalam sistem.

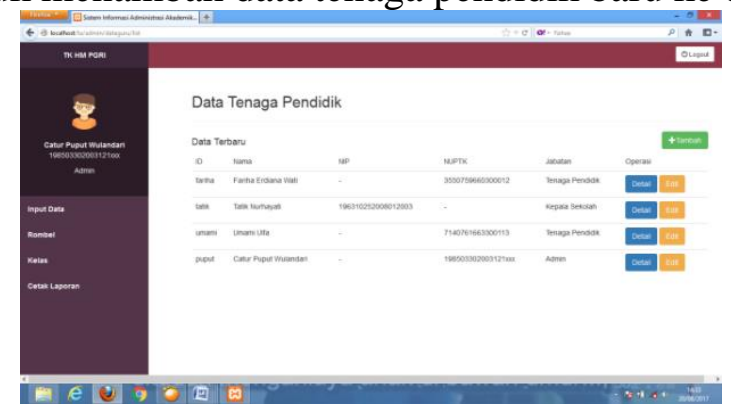

Gambar 7.Halaman Data Tenaga Pendidik

\subsection{Halaman Utama Tenaga Pendidik}

Halaman ini berisi banyak form seperti form data-data dan logout. Tenaga pendidik dapat menginputkan data-data pada form ini dengan memilih salah satu form yang diinginkan.

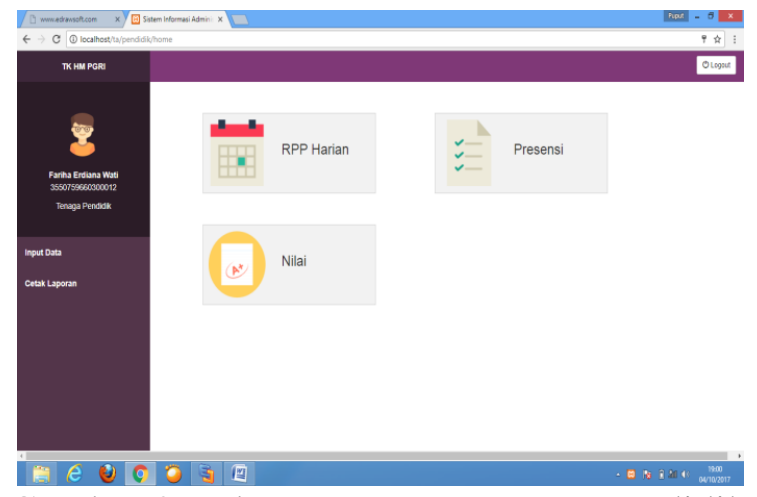

Gambar 8.Halaman Utama Tenaga Pendidik 


\subsection{Halaman Presensi}

Halaman ini berisi form yang digunakan tenaga pendidik untuk melakukan presensi anak didik setiap hari.

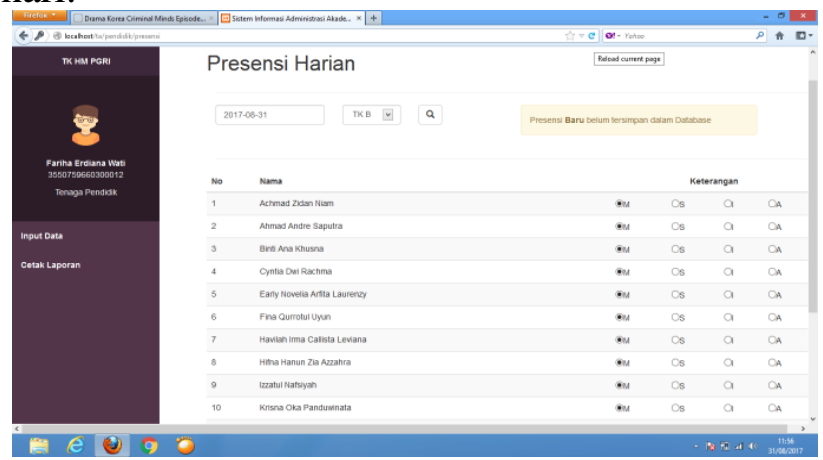

Gambar 9. Presensi Anak Didik

\subsection{Halaman Rencana Pelaksanaan Pembelajaran Harian (RPPH)}

Halaman ini berisi form yang digunakan tenaga pendidik untuk memasukkan rencana pelaksanaan pembelajaran harian.

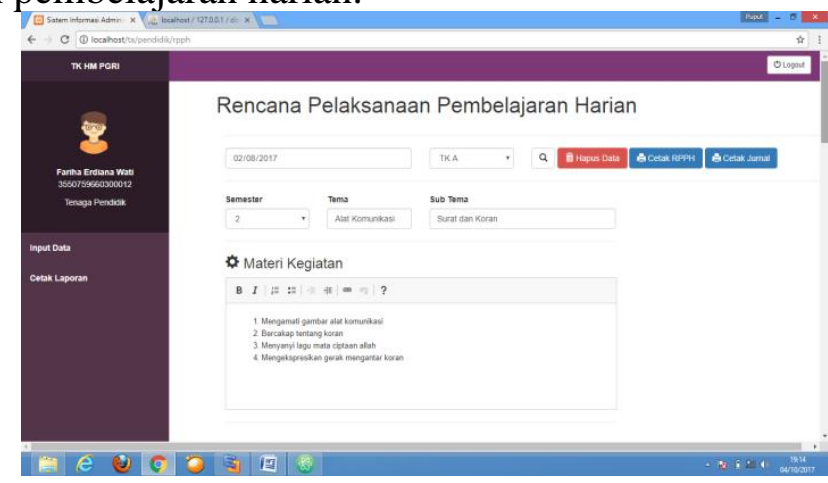

Gambar 10. Halaman RPPH

\subsection{Halaman Nilai}

Halaman ini berisi form yang digunakan tenaga pendidik untuk memasukkan nilai anak didik setiap harinya .

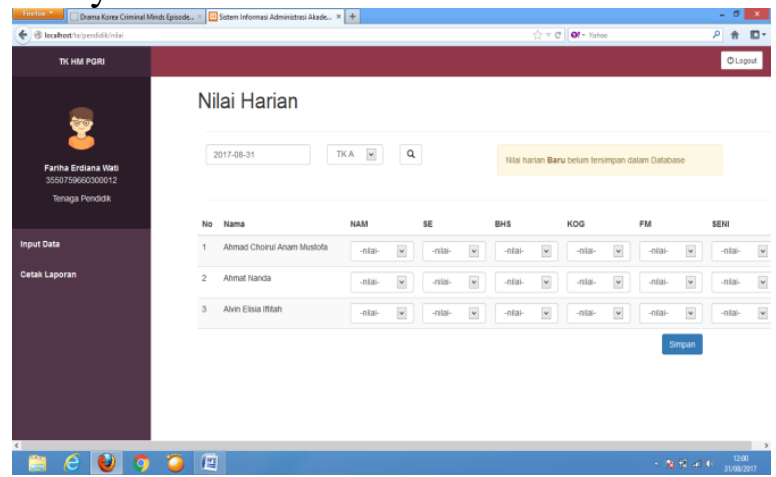

Gambar 11. Halaman Nilai

\subsection{Cetak Rapor}

Halaman ini berisi form yang digunakan tenaga pendidik untuk mencetak rapor anak didik. 


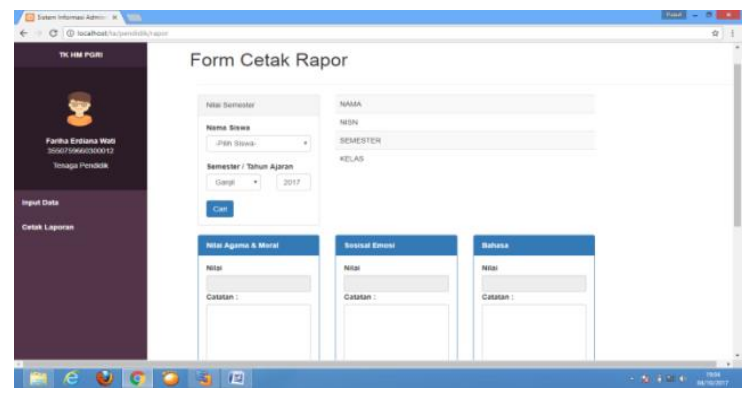

Gambar 12. Halaman Cetak Rapor

\section{KESIMPULAN}

Penelitian ini berhasil membuat sistem informasi administrasi tenaga pendidik untuk mengolah data anak didik, tenaga pendidik, presensi, jurnal mengajar, rencana pelaksanaan pembelajaran harian, nilai dan rapor anak didik menjadi lebih cepat dan mudah. Dengan adanya sistem informasi administrasi tenaga pendidik memudahkan para tenaga pendidik dalam menyimpan data administrasi tenaga pendidik dan data anak didik. Pada program sistem informasi administrasi tenaga pendidik diharapkan para tenaga pendidik di taman kanak-kanak HM PGRI Sonorejo lebih aktif dan kreatif dalam memanfatkan sistem teknologi yang semakin canggih. Diharapkan untuk penelitian berikutnya mahasiswa mampu melakukan pengembangan program pada nilai rapor dengan berbentuk grafik.

\section{DAFTAR PUSTAKA}

[1] Departemen Pendidikan Nasional. 2003. Undang-Undang Nomor 20 Tahun 2003. Tentang Sistem Pendidikan Nasional. Jakarta: Depdiknas.

[2] Devung, Simon. (1998). Pengantar Ilmu Administrasi dan Manajemen. Jakarta : Departemen Pendidikan dan Kebudayaan, Direktorat Jendral Pendidikan Tinggi, Pengembangan Lembaga Pendidikan dan Tenaga Pendidik

[3] Davis, G. B. (1993). Kerangka Dasar Sistem Informasi Manajemen. (Terjemahan Andreas S. Adiwardana). Jakarta: PT. Pustaka Binama Pressindo.

[4] Kamus Besar Bahasa Indonesia/ Tim Penyusun Pusat Bahasa. (2002). Ed. 3.- Cet.2 - Jakarta :Balai Pustaka. 